\title{
Numerical simulation of the diurnal cycle of rainfall in SW Amazon basin during the 1999 rainy season: the role of convective trigger function
}

\author{
Cláudio Moisés Santos e Silva • \\ Saulo Ribeiro de Freitas • Ralf Gielow
}

Received: 30 September 2010 / Accepted: 12 December 2011 / Published online: 7 February 2012

(C) Springer-Verlag 2012

\begin{abstract}
In continental areas, the maximum rainfall simulated with the Brazilian developments on the Regional Atmospheric Modeling System (BRAMS) occurs around $4 \mathrm{~h}$ earlier than the one observed with rain gauges. This work presents the successful implementation of a new convective trigger function (CTF) in the convective parameterization scheme used in BRAMS that corrects this misfit between model and observations. The importance of the CTF formulation on the diurnal cycle of rainfall over the Amazon Basin is reflected by the following numbers: Over Rondonia (SW Amazonia), the original version of BRAMS simulates the maximum rainfall at 1400 UTC (1000 LST), with the new CTF maximum shifting to 1800 UTC (1400 LST), while the S-band radar rainfall maximum is at 1900 UTC (1500 LST). This is attributed to two factors: (1) the new CTF is now coupled to the sensible and latent heat fluxes at surface; (2) during the early morning, the convective available potential energy is reduced.
\end{abstract}

\section{Introduction}

The diurnal cycle is a climatic variability mode determined primarily by solar incoming radiation, which controls the surface processes, such as diabatic heating/cooling and mass/ momentum exchange by turbulent processes. The diurnal

\section{M. S. e Silva $(\square)$}

Departamento de Física Teórica e Experimental (DFTE), Universidade Federal do Rio Grande do Norte (UFRN), Campus Universitário, $\mathrm{s} / \mathrm{n}$,

CEP: 59072-970 Natal, Rio Grande do Norte, RN, Brazil

e-mail: claudio@dfte.ufrn.br

S. R. de Freitas $\cdot$ R. Gielow

Centro de Previsão de Tempo e Estudos Climáticos (CPTEC),

Instituto Nacional de Pesquisas Espaciais (INPE),

São Jose dos Campos, São Paulo, Brazil cycle of rainfall exhibit a coherent behavior over land and ocean. Yang and Smith (2006) performed a comprehensive review of the mechanisms for diurnal variability, classifying them in ocean/land and day/night types. In general, over ocean areas, the maximum rainfall is observed during late-eveningearly-morning while, over land, the maximum is mid- to late afternoon hours. However, different mechanisms can coexist, implying semidiurnal cycles over both continental and ocean areas (Yang et al. 2008).

Specifically over the Amazon basin, the diurnal cycle of rainfall is modulated by meteorological systems and landscape heterogeneity (forested and deforested regions). Among the meteorological systems, squall lines that form in coastal regions account for the maximum rainfall during mid- to late afternoon (Kousky 1980). Eventually, these squall lines reach the central portion of the Amazon basin (Greco et al. 1990; Cohen et al. 1995), during their propagation into the interior of the continent; they trigger nocturnal precipitation in regions up to $2,000 \mathrm{~km}$ from their origin (Rickenbach 2004). Other studies have focused the diurnal cycle of rainfall as a result of the influence of low level jets east of the Andes (Marengo et al. 2004), shallow convection (Pereira and Rutledge 2006), interaction between gust fronts and topography (Lima and Wilson 2008), and South Atlantic Convergence Zone occurrence (Rickenbach et al. 2002; Strong et al. 2005).

Concerning the land use, several studies have been focused on the influence of deforestation in the hydrological cycle and cloud cover over the Amazon basin (Wang et al. 2000; Roy and Avissar 2002; Machado et al. 2002, 2004; Silva Dias et al. 2002a; Durieux et al. 2003; Negri et al. 2004; Wang et al. 2009; Saad et al. 2010). On the diurnal rainfall cycle, results obtained by numerical model have shown that, during the dry season, mesoscale circulation are formed by contrast between forest and deforested areas modifying the cloud depths (Wang 
et al. 2009) and influencing the spatial distribution of rainfall (Wang et al. 2000; Silva Dias et al. 2002a, b; Saad et al. 2010). On the large scale, satellite data have shown that, over deforestation regions, the seasonality and the diurnal cycle are most pronounced compared with forest areas (Durieux et al. 2003; Machado et al. 2004; Negri et al. 2004).

Due to the complexity of the physical processes that modulate the diurnal cycle, numerical models that use cumulus parameterizations to simulate rainfall often fail to reproduce the diurnal cycle. Betts and Jakob (2002) suggest that this could be associated with an underestimation in the models of the role of shallow cumulus. The instability and moisture of environment in presence of shallow cumulus controls the transition from shallow to deep convection (Kuang and Bretherton 2006; Wu et al. 2009), and this transition is not well-represented in the models.

Some issues can cause improvements in the diurnal cycle of rainfall simulation: the super-ensemble technique (Krishnamurti et al. 2007), grid refinement (Sato et al. 2009), use of cloud resolving models (e.g., Lang et al. 2007), better representation of physical processes in the atmospheric boundary layer (Rio et al. 2009), and appropriate entrainment rate (Del Genio and $\mathrm{Wu} 2010$ ); in addition, the convective trigger function (CTF) formulation. The CTF is a hierarchical decision-making function that controls the employment of the convection scheme at each grid point in the model (Kain and Fritsch 1992). Bechtold et al. (2004) achieved improvements in diurnal cycle of rainfall simulation over the Amazon basin after implementing the CTF developed by Jakob and Siebesma (2003) (henceforth referred to as JS03) in the Tiedtke (1989) parameterization. The present works' objective is to analyze the impact in diurnal cycle of rainfall over the Amazon basin during the 1999 rainy season, simulated through Brazilian developments on the Regional Atmospheric Modelling System (BRAMS; Freitas et al. 2009) with the Grell and Devenyi (2002) (henceforth referred to as GD02) parameterization using the Jakob and Siebesma (2003) convective trigger function.

\section{Methodology}

\subsection{Rainfall dataset}

Data collected during the 1999 rainy season (January to February) intensive campaign of the Tropical Rainfall Measuring Mission (TRMM) that occurred jointly with the Large-Scale Biosphere-Atmosphere Experiment in Amazonia (LBA) (TRMM-LBA; Silva Dias et al. 2002b) were used. The precipitation was obtained through an $\mathrm{S}$ band polarimetric radar (S-POL) installed in the municipality of Presidente Médici $\left(12.22^{\circ} \mathrm{S} ; 61.99^{\circ} \mathrm{W}\right)$, with a frequency of $3 \mathrm{GHz}$, a wavelength of $10.7 \mathrm{~cm}$, and a sweep area radius of $100 \mathrm{~km}$.
The methods for obtaining and validating the precipitation rates from the rain gauge data were presented by Carey et al. (2000). In addition, the S-POL radar data showed very good correlation with the rain gauge data on a diurnal scale (Santos e Silva et al. 2009). The data are available on a 2-km grid with 100 by 100 grid points. The sweeps occur in intervals of approximately $10 \mathrm{~min}$, and the average hourly precipitation was computed with the sweep data from a half hour before to a half hour after the full hour.

\subsection{Grell and Devenyi (2002) parameterization}

The GD02 parameterization is a mass flux-type scheme based on the work of Grell (1993). Entrainment and detrainment are inversely proportional to a fixed-cloud radius (in the present study, $12 \mathrm{~km}$ ). The central idea of GD02 is to construct ensembles of parameterizations by varying parameters associated with dynamic control, static control, and feedback. The principal forms of producing ensemble members based on static control and feedback, precipitation efficiency, and entrainment rate. With relation to dynamic control, different closure options are used, which are based on the concept of convective quasi-equilibrium, convective adjustment, or moisture convergence.

\subsection{The convective trigger function of Grell and Devenyi} (2002)

The GD02 work CTF is no directly described; however, it is described in Grell (1993) and Grell et al. (1994). The CTF works as follows: A parameter (CAPMAX) is defined and indicates the maximum height that the cloud base can be identified. A parcel originating at the level of highest moist static energy $\left(z_{\mathrm{b}}\right)$ ascends adiabatically. The first triggering condition, which is that $z_{\mathrm{b}}$ must be found below CAPMAX. The cloud base height is the level of free convection of the parcel ascending from. The cloud top $\left(z_{\mathrm{t}}\right)$ is the level of zero buoyancy of the parcels. Another imposition of the CTF is that the height in meters (cloud depth) between $z_{\mathrm{b}}$ and $z_{\mathrm{t}}$ should be larger than a minimum height ( $5 \mathrm{~km}$ in our case). Thus, the CTF is principally dependent on the choice of the values of CAPMAX and the minimum cloud depth.

\subsection{The Jakob and Siebesma (2003) convective trigger function}

The method developed by JS03 is used to determinate the location, cloud type (based on depth between the base and the top), and thermodynamics proprieties of the base and top of clouds. A generic equation is used to diagnose the updraft moist static energy $(h)$ and the total specific humidity $\left(q_{\mathrm{t}}\right)$. 
The evolution with height of the updraft thermodynamics properties is determined by

$\frac{\partial \varphi_{\text {up }}}{\partial z}=-\mu\left(\varphi_{\text {up }}-\bar{\varphi}\right)$, with $\varphi=\left\{h, q_{t}\right\}$

Where $\Delta z$ is the vertical grid spacing, and entrainment $(\mu)$ is determined by the relation:

$\mu \approx \frac{0.55}{\Delta z}$

The algorithm is initialized with the $h$ and $q_{\mathrm{t}}$ fields at the lowest model level $z_{1}$. The fields at this level are perturbed by the contributions of surface sensible and latent heat fluxes, according to:

$\varphi_{\operatorname{up}\left(z_{1}\right)}=\overline{\varphi_{z_{1}}}+\frac{w^{\prime} \varphi^{\prime}}{\sigma_{w\left(Z_{1}\right)}}$

Where $\overline{w^{\prime} \varphi_{s}^{\prime}}$ is the surface sensible and latent heat flux. The $\sigma_{w\left(z_{1}\right)}$ term is the standard deviation of the vertical velocity at the level closest to the surface

$\frac{\sigma_{w}}{w_{*}} \approx 1,2\left[\left(\frac{u_{*}}{w_{*}}\right)^{3}-0,6 \frac{z}{z_{i}}\right]^{\frac{1}{3}}$

$w$ is the convective velocity scale, and $u$ is the surface friction velocity. In addition to the updraft properties, $h$ and $q_{t}$, the algorithm contains an explicit diagnostic equation to calculate the vertical velocity $w_{\text {up }}$ through the equation:

$w_{\text {up }} \frac{\partial w_{\text {up }}}{\partial z}=-c_{1} \mu w_{\text {up }}^{2}+c_{2} B$

At the first level, the boundary condition $w_{\operatorname{up}\left(z_{1}\right)}=\sigma_{w}$ is applied. The parameters $c_{1}$ and $c_{2}$ were constants that can be used to sensitivity testing; in our case, $c_{1}=c_{2}=1$. The first term on the right hand side of Eq. 5 is associated with the entrainment rate, acting to dissipate the kinetic energy of the updraft, while the second term represents the contribution of buoyancy to the total kinetic energy, where:

$B=g \frac{\left(\theta_{\mathrm{v}, \text { up }}-\bar{\theta}_{\mathrm{v}}\right)}{\bar{\theta}_{\mathrm{v}}}$

in which $\theta_{v}$ is the virtual potential temperature, with the overbar signifying a spatial average. The ascending parcel possesses properties of an average atmosphere at a height of $60 \mathrm{hPa}$; thus, as a good approximation, the parcel has physical properties representative of the atmospheric boundary layer.

Based on set of Eqs. 1-6, the CTF works as following: (1) $\sigma_{w}$ is calculated (Eq. 4); (2) perturbations in the first level of model is determined (q. 3); (3) vertical profile of entrainment rate is defined (Eq. 2); (4) $h$ and $q_{t}$ profile are diagnosed (Eq. 1); (5) the cloud base is found; (6) the updraft vertical velocity profile is calculated (Eq. 5). The trigger condition is if vertical velocity is positive in the cloud base. The cloud top is the level which the vertical velocity vanish. The cloud type is based in the depth between the base and top cloud, with a minimum of $200 \mathrm{hPa}$ for deep convection.

\subsection{Regional atmospheric model}

The BRAMS model is a version adapted to the tropics of version 6 of the RAMS model (Walko et al. 2000). RAMS is a non-hydrostatic model constructed to simulate small atmospheric eddies to planetary scale motions. Details on the differences between version 6.0 of the RAMS model and version 4.0 of the BRAMS model can be found in Freitas et al. (2009), with the principal changes being: (1) inclusion of the GD02 mass flux convective scheme; (2) daily soil moisture estimates; (3) an updated vegetation cover map; (4) soil classifications specific to Brazil;

Fig. 1 The TRMM-LBA area.

The S-POL domain correspond to the shaded circle, and the square one, the region considered for the numerical experiments with BRAMS model

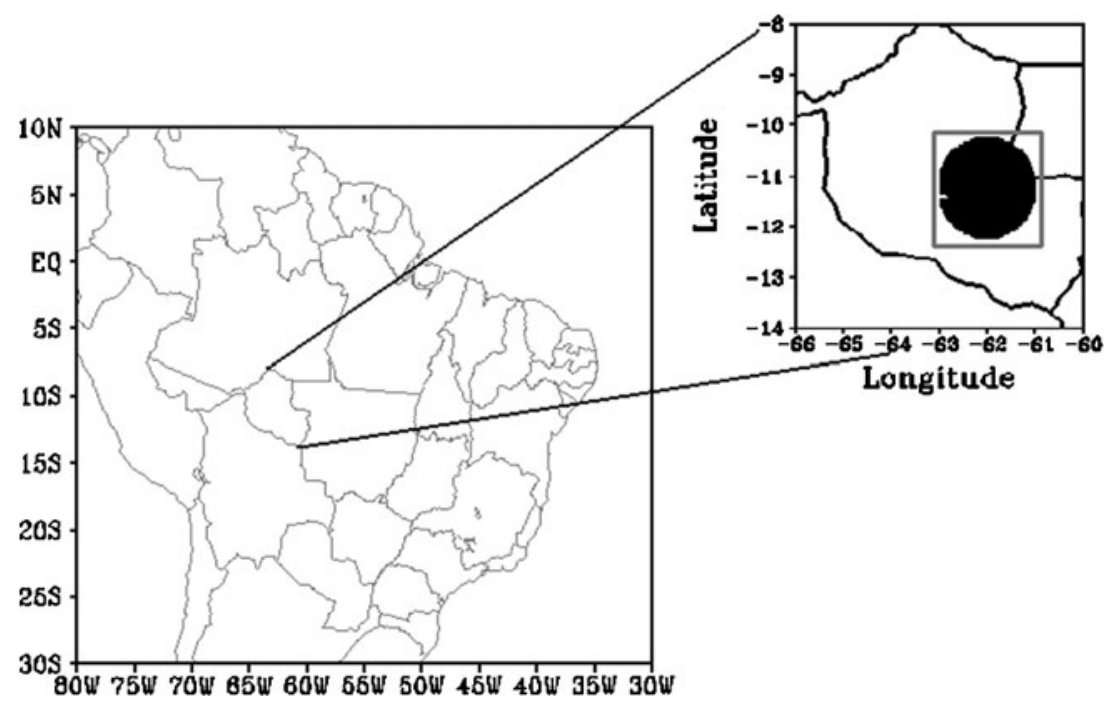


(5) Normalized Difference Vegetative Index data from the Moderate Resolution Imaging Spectroradiometer sensor.

\subsection{Numerical experiments}

The large-scale initial and boundary conditions were obtained from the European Centre for Medium-Range Weather Forecasts global model reanalysis, with $2.5^{\circ}$ grid spacing and updated every $6 \mathrm{~h}$. The simulation grid had a horizontal spacing of $25 \mathrm{~km}$, centered at latitude $5.0 \mathrm{~S}$, and longitude $62.0 \mathrm{~W}$. Three hundred points were used in the zonal direction and 200 in the meridional direction. In the vertical direction, 40 levels were used, with initial spacing of $150 \mathrm{~m}$ and an increment ratio of 1.07 up to a maximum spacing of $950 \mathrm{~m}$, resulting in a vertical domain of $22 \mathrm{~km}$. The soil was composed of seven layers, with depths of 0.02 , $0.06,0.14,0.30,0.62,1.26,2.54$, and $5.10 \mathrm{~m}$. The simulations were initiated at 0000 UTC on 16 January 1999 and
Fig. 2 Diurnal cycle of rainfall rate simulated in CTRL1 and NRAS8 experiments and observed via S-POL radar and rain gauges (a); convective available potential energy (b); sensible heat flux observed during February at REBIOJaru, LBA site (c); same as c, but for latent heat flux (d)
0

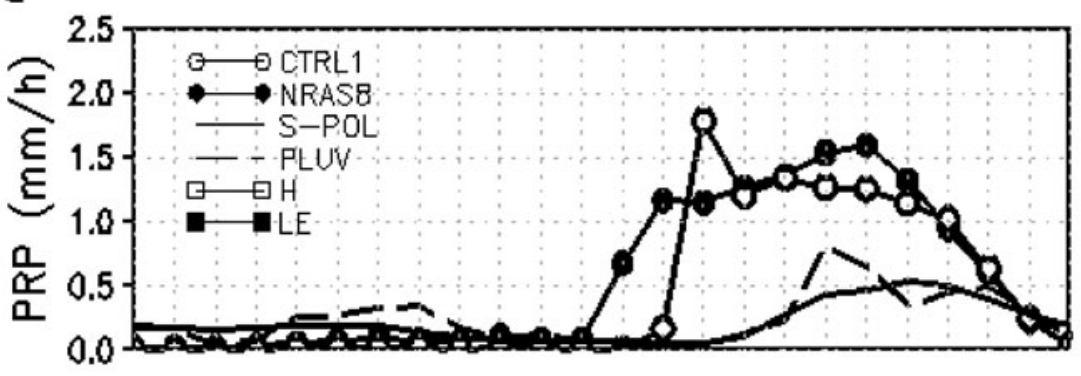

b

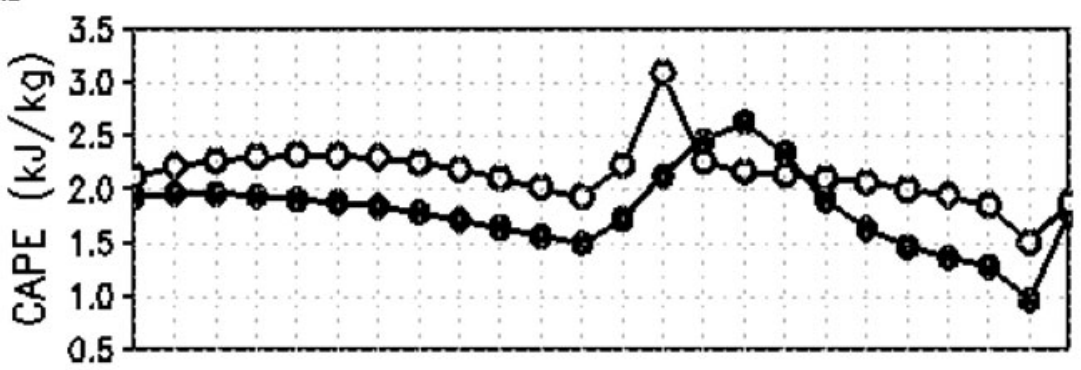

C

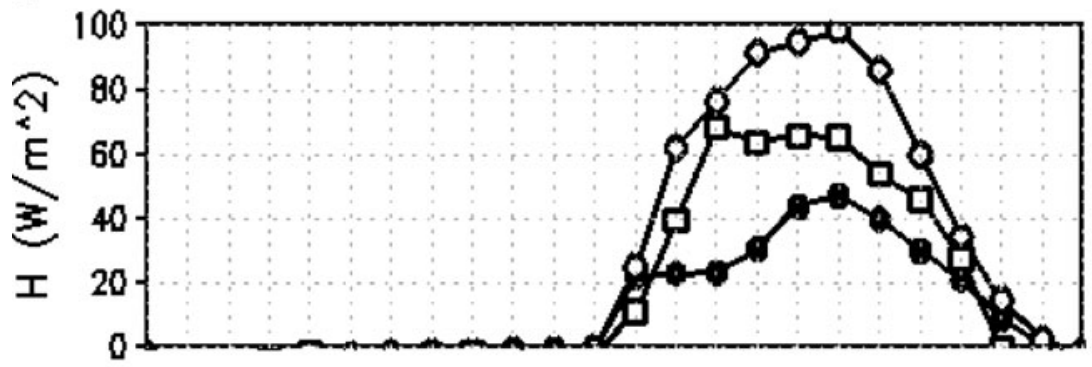

d

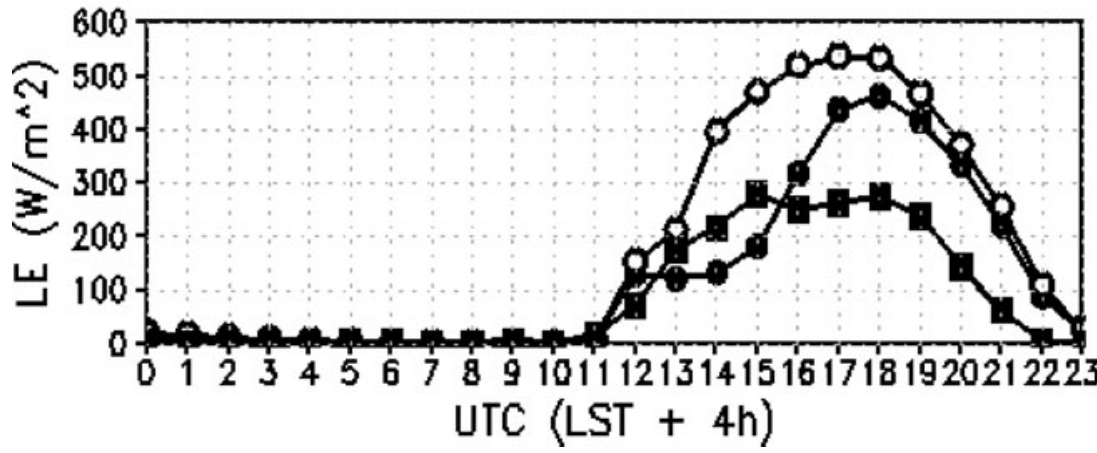


ran until 2300 UTC on 28 February 1999, with a time step of $30 \mathrm{~s}$. In both experiments, the ensemble closure deep convection parameterization of GD02 was used, and the only difference was the utilization of the GD02 CTF in the first experiment (denoted CTRL1) and the JS03 CTF in the second experiment (denoted NRAS8). The area used to evaluate the simulations and the S-POL radar domain was shown in the Fig. 1.

\section{Results}

\subsection{General aspects}

In Fig. 2, the diurnal cycle of convective available potential energy (CAPE), sensible (H), and latent (LE) heat fluxes and hourly precipitation rate are shown. In the CTRL1 experiment, the CAPE reaches its maximum value of $3,200 \mathrm{Jkg}^{-1}$ at $1300 \mathrm{UTC}$ and convection removes $800 \mathrm{Jkg}^{-1}$ in the following hour, which determines the precipitation maximum of $1.8 \mathrm{~mm} \mathrm{~h}^{-1}$ at this time. After this time, the atmosphere becomes stable and does not again attain thermodynamically favorable conditions for the accumulation of potential energy. The CAPE in the CTRL1 experiment is always larger than that in the NRAS 8 experiment, except between 1400 and 1600 UTC. This is due to the parcel criterion used in each CTF. Since GD02 considers the low-level vertical layer with the largest moist static energy, the ascending parcel is more statically unstable than the well-mixed parcel in JS03. The average CAPE in CTRL1 is 2,100 and $1,800 \mathrm{Jkg}^{-1}$ in the NRAS8 experiment, while observations from radiosondes conducted during the TRMM-LBA experiment show a CAPE of around 1,200 $\mathrm{Jkg}^{-1}$ (Halverson et al. 2002; Fisch et al. 2004).

In the NRAS8 experiment, a strong coupling between precipitation and surface sensible and latent heat fluxes was observed. In agreement with Eq. 3, the larger the sum of the
Fig. 3 Diurnal cycle of diabatic heating $\left(Q_{1}\right)$ : NRAS8 $(\mathbf{a})$, and CTRL1 (b) experiments. Diurnal cycle of driest $\left(Q_{2}\right)$ : NRAS8 (d), and CTRL1 (e) experiments; mean profile of $Q_{1}$ (c), and $Q_{2}$ (f)

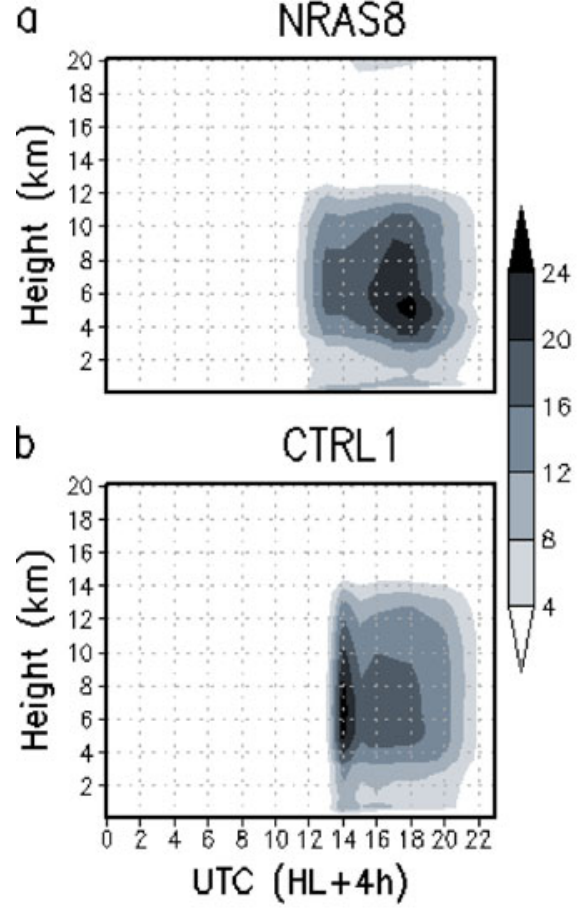

C

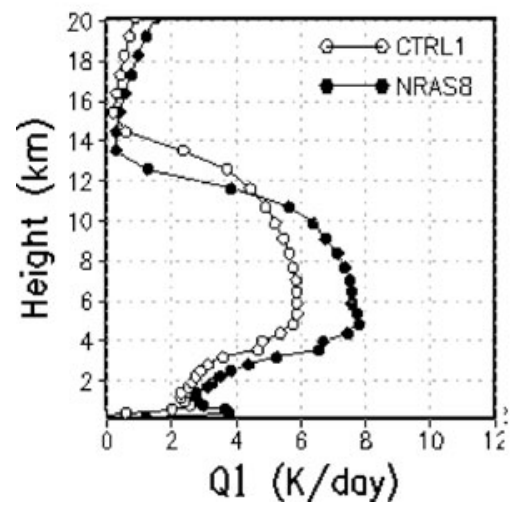

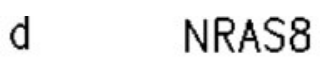

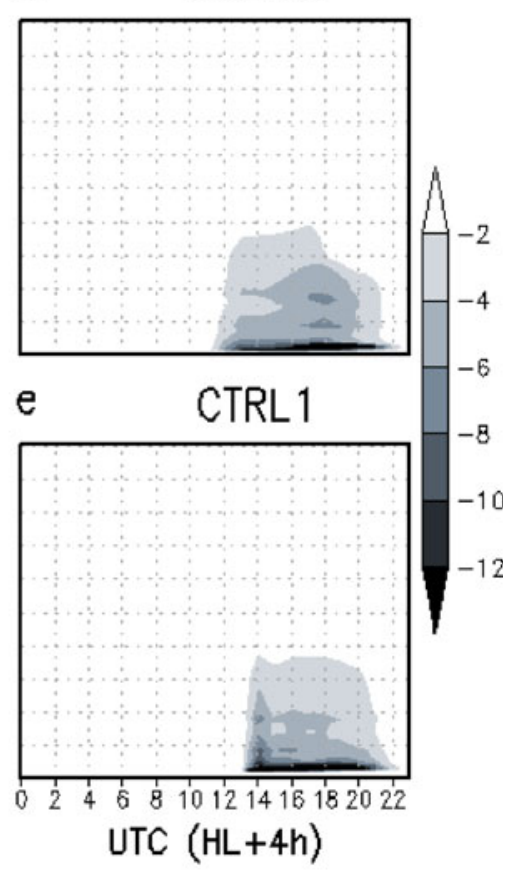

f

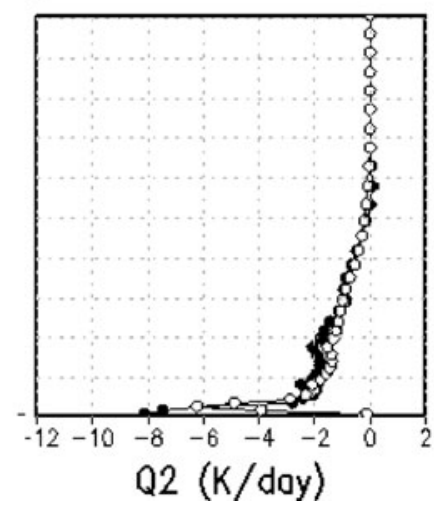


fluxes $(H+L E)$, the larger the perturbation caused in the lowest model level, and thus the larger the probability of the parcel to acquire positive buoyancy and develop convection. The observed $\mathrm{H}$ diurnal cycle shows a maximum of $63 \mathrm{Wm}^{-2}$ at $1400 \mathrm{UTC}$, and $\mathrm{H}$ is maintained practically constant until 1700 UTC, when it finally diminishes. The latent heat flux shows a similar pattern, but the observed maximum of $300 \mathrm{Wm}^{-2}$ occurs at $1500 \mathrm{UTC}$.

The observed Bowen ratio $\left(\beta=\frac{H}{\mathrm{LE}}\right)$ has an average value of 0.27 and varies from 0.20 to 0.35 between 0800 UTC and 2100 UTC, typical of forested regions during the rainy period in the Amazon basin (Rocha et al. 2004, von Randow et al. 2004). In the CTRL1 and NRAS8 experiments, $\beta$ has an average value of 0.20 and 0.16 , respectively. That is, the model overestimates the sensible and latent heat fluxes, however, the magnitude of the overestimation is greater in sensible flux, a fact early verified by Chou et al. (2002), who conducted simulations with the Eta/SSiB (Simplified Simple Biosphere Model) model over the South America.

The apparent heat source $\left(Q_{1}\right)$ and moisture sink $\left(Q_{2}\right)$ profiles (Yanai et al. 1973) due to deep convection are shown in Fig. 3. In the NRAS8 experiment, the maximum value of $Q_{1}$ is $24 \mathrm{Kday}^{-1}$ at $1800 \mathrm{UTC}$ at around $5 \mathrm{~km}$, and the maximum cloud development height is $12 \mathrm{~km}$. There is a gradual evolution of convective activity starting at 0800 UTC, which is in phase with the hourly evolution of sensible and latent heat fluxes shown in Fig. 2c, d. In the CTRL1 experiment, convective activity is most intense at 1400 UTC, when $Q_{1}$ also attains a maximum of $24 \mathrm{Kday}^{-1}$ and the cloud height reaches around $14 \mathrm{~km}$. Between 1500 and $1800 \mathrm{UTC}$, $Q_{1}$ does not exceed $20 \mathrm{Kday}^{-1}$, although the cloud height is around $2 \mathrm{~km}$ higher than that in the NRAS8 experiment.
The convective activity causes an intense drying close to the surface in both experiments, which is shown in the diurnal cycle of $Q_{2}$ (Fig. 3d, e). In the NRAS 8 experiment, the drying up to $1 \mathrm{~km}$ is $-12 \mathrm{Kday}^{-1}$ between 1200 UTC and $2100 \mathrm{UTC}$, and at $1800 \mathrm{UTC}^{\mathrm{U}}$, heating rates on the order of $-6 \mathrm{Kday}^{-1}$ are seen up to height of $5 \mathrm{~km}$. In the CTRL1 experiment, $Q_{2}$ is also on the order of $-12 \mathrm{Kday}^{-1}$, although isolines of $-6 \mathrm{Kday}^{-1}$ are seen at $1400 \mathrm{UTC}$. The average profile of $Q_{1}$ (Fig. 3c) shows that convective activity is more intense and less deep in the NRAS8 experiment than in the CTRL1 experiment. The maximum diabatic heating in NRAS 8 is $8 \mathrm{Kday}^{-1}$ at $5 \mathrm{~km}$ while, in the CTRL1 simulation, it is $6 \mathrm{Kday}^{-1}$ at $6 \mathrm{~km}$. The $Q_{2}$ profile shows that, up to $1 \mathrm{~km}$, both experiments produce drying rates of $-8 \mathrm{Kday}^{-1}$, and in the layer from 2 to $5 \mathrm{~km}$, the NRAS8 simulation produces a profile $0.5 \mathrm{Kday}^{-1}$ dryer than the CTRL1 simulation.

The $Q_{1}$ profiles calculated from TRMM-LBA observations reveal maximums on the order of $5 \mathrm{Kday}^{-1}$ around $400 \mathrm{hPa}$ and rates less than $1 \mathrm{Kday}^{-1}$ in the layer from the surface up to $850 \mathrm{hPa}$ (Schumacher et al. 2007). This suggests that the formation of shallow cumulus was observed during TRMM-LBA, in addition to stratiform cloudiness. Comparing the results presented here (Fig. 3c) with the conclusions of Schumacher et al. (2007), it is perceived that both experiments overestimate the maximum of $5 \mathrm{Kday}^{-1}$ as well as the minimum of $1 \mathrm{Kday}^{-1}$. However, in the NRAS8 experiment, it was verified that the simulated cumulus clouds are less deep and therefore more consistent with the results of these authors.

With the use of the JS03 CTF, it was verified that the simulated maximum convective activity changes from 1400
Fig. 4 Mean daily of zonal wind component: measuring by radiosondes at Nossa Senhora farm (a), simulated by CTRL1 (b) and NRAS8 (c) experiments

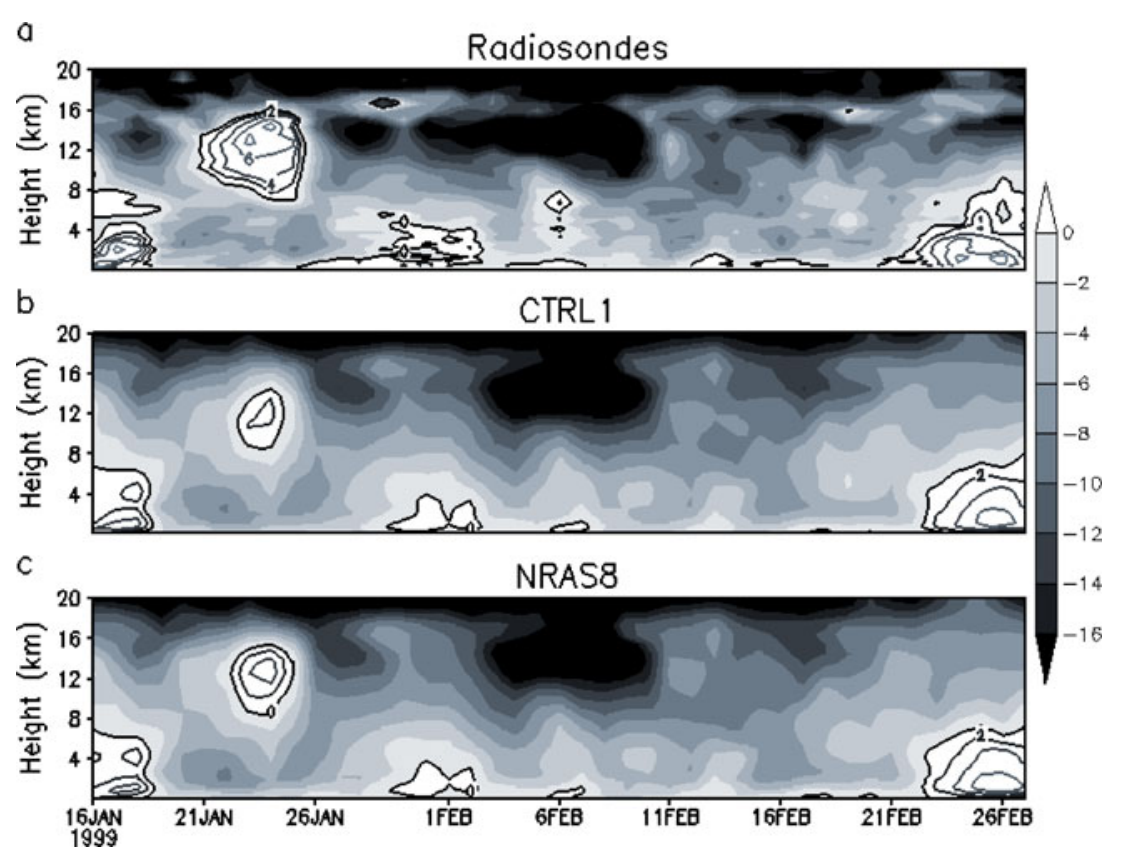


Table 1 The $2 \times 2$ contingency table

\begin{tabular}{lll}
\hline Simulation & \multicolumn{2}{l}{ Radar precipitation } \\
\cline { 2 - 3 } & Yes & No \\
\hline Yes & a & b \\
No & c & d \\
\hline
\end{tabular}

UTC to 1800 UTC, that is, there was a 4-h phase delay from the NRAS8 to CTRL1 experiments. In a similar study, Bechtold et al. (2004) verified that the most intense convective activity moved from 1330 UTC to 1600 UTC with the use of the JS03 CTF. Despite the discrepancy between the numbers of hours in the phase shift, which can be attributed to the use of different regional models, among other factors, the consistency of these results is verified. In addition, the JS03 algorithm was tested together with other CTF in different convective cloud parameterizations, but for simulations with global models (Tost et al. 2006). Although these authors did not focus on the diurnal cycle, the use of this CTF showed improvements in the spatial distribution as well as seasonality of precipitation.

\subsection{Intraseasonality}

The simulated and observed (via radiosondes) zonal wind components are shown in Fig. 4. In both experiments, the model is capable of reproducing with relative precision the wind patterns at low and high levels in agreement with the radiosonde data. However, the model tends to underestimate the absolute value of the observed zonal wind component. It is noted that the data obtained from the radiosondes are interpolated to a vertical grid with fixed $25-\mathrm{m}$ spacing, while the model vertical spacing has a minimum of $150 \mathrm{~m}$ close to
Fig. 5 Rainfall, sensible and latent heat fluxes, and CAPE diurnal cycle simulated by CTRL1 and NRAS8 experiments
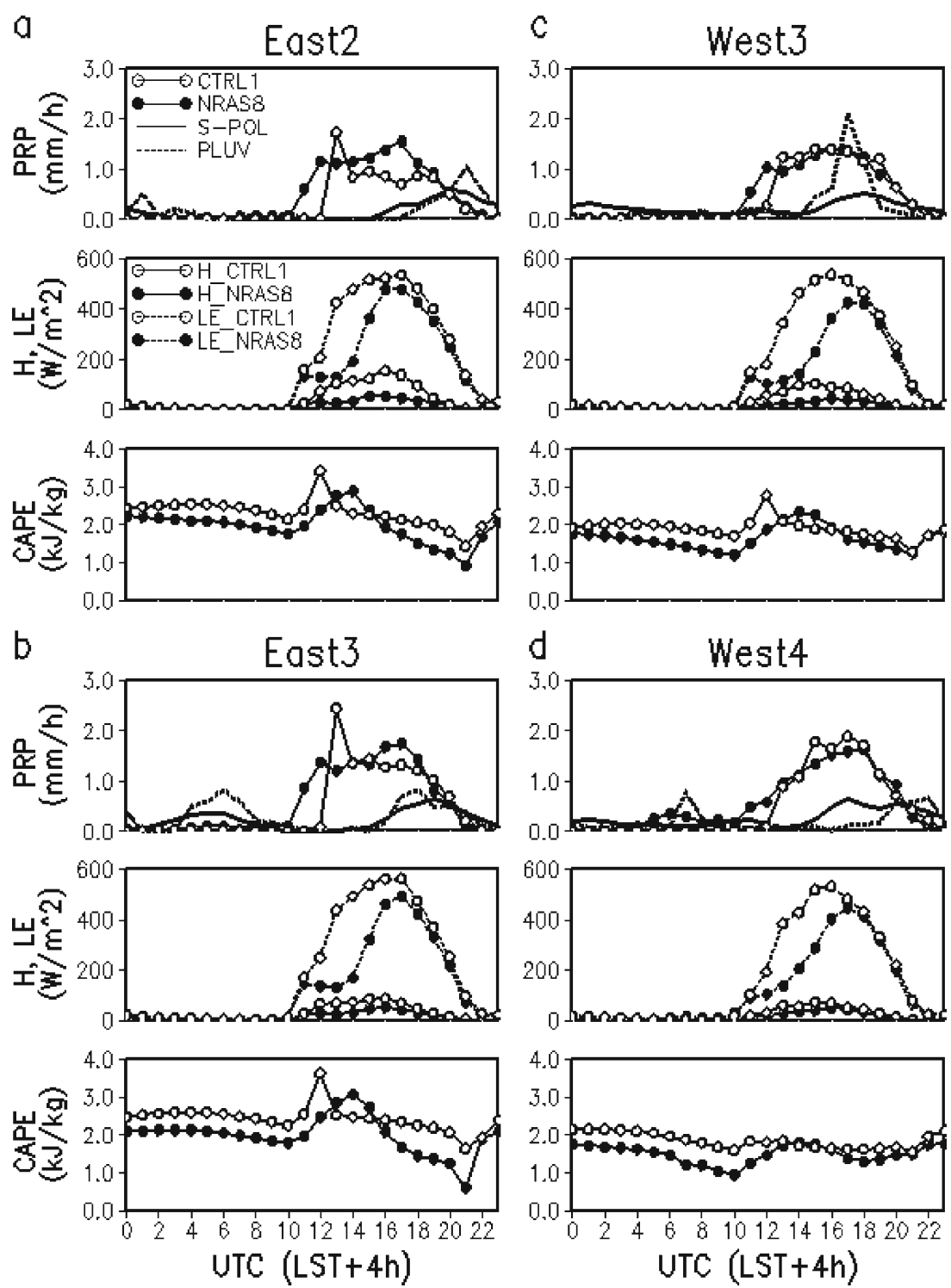
the surface. In addition, the maximum number of soundings per day never exceeds eight profiles, while the daily average of the simulations is taken of 24 hourly points. However, despite some differences in intensity, it can be said that the model coherently reproduced the regimes listed in Table 1. With relation to the experiments, it was verified that NRAS8 tend to present more intense velocities than CTRL1, which can be verified, for example, from 23 to 25 January when the observed zonal velocity at the $12 \mathrm{~km}$ level had a maximum of $8 \mathrm{~ms}^{-1}$ while, in the NRAS8 and CTRL1 experiments, the maximum velocities were 6 and $4 \mathrm{~ms}^{-1}$, respectively.

The diurnal cycle of rainfall simulated in CTRL1 and NRAS8, the precipitation observed with S-POL radar, the sensible and latent heat fluxes, and simulated CAPE are shown in Fig. 5. During the East2 regime, the CTRL1 experiment shows a precipitation maximum at 1400 UTC while, in the NRAS8 experiment, the maximum occurs at
1800 UTC, associated with the surface flux coupling. Nocturnal precipitation is observed during the East3 regime, with a maximum around 0600 UTC, which is associated with the passage of squall lines over the region (Rickenbach 2004).

The nocturnal precipitation causes surface moistening and consequently an advancement of the afternoon precipitation maximum in the East3 regime relative to the East2 regime. In this way, it was verified that, in the East3 regime, the principal precipitation maximum observed with S-POL occurred at 1900 UTC with an intensity of $0.7 \mathrm{~mm} \mathrm{~h}^{-1}$. Although the model does not adequately simulate the nocturnal precipitation intensity, this precipitation phase advancement is represented, because the CAPE accumulation as well as the $\mathrm{H}$ and LE fluxes have advanced cycles in this regime. Thus, the precipitation maximum is simulated at 1300 UTC in the CTRL1 experiment and at 1700 UTC in the NRAS8 experiment.
Fig. 6 Diurnal cycle of $Q_{1}$ $\left(\mathrm{K}\right.$ day $\left.^{-1}\right)$ vertical profile simulated in NRAS8 and CTRL1 experiments by easterly and westerly low level wind regimes
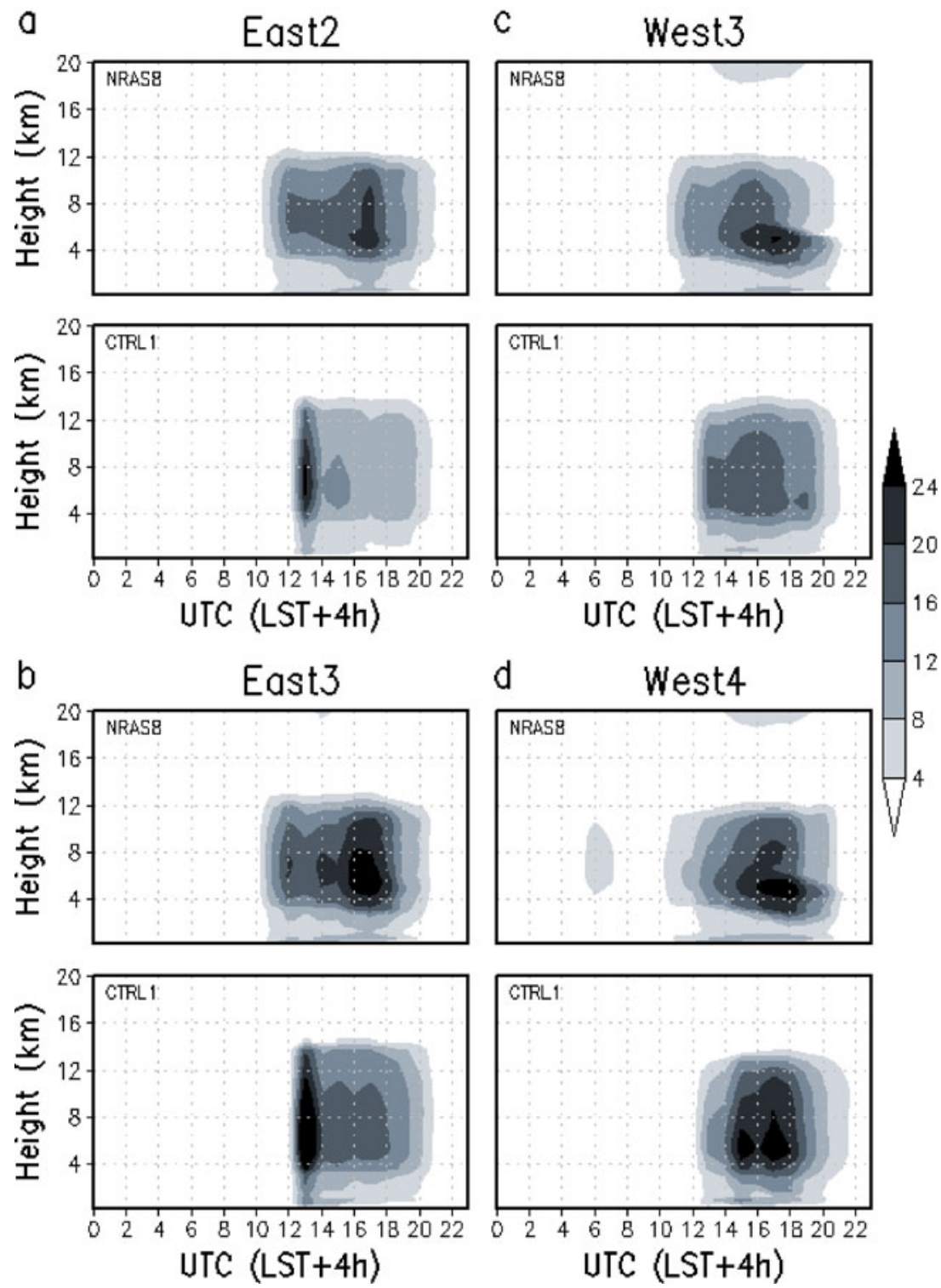
Since CAPE is smaller during west regimes, the abrupt precipitation maximum at the beginning of the morning verified in the CRTL1 simulation is diminished. In the West 3 regime, CAPE is $3,000 \mathrm{Jkg}^{-1}$ at $1200 \mathrm{UTC}$, while in the east regimes CAPE is around $3,600 \mathrm{Jkg}^{-1}$. In both experiments, the precipitation maximum of the West3 regime occurs at 1700 UTC and with a similar intensity of $1.5 \mathrm{~mm} \mathrm{hr}^{-1}$. However, what differs in the two simulations is the earlier initiation of precipitation in NRAS8 and a secondary maximum of $1.3 \mathrm{~mm} \mathrm{~h}^{-1}$ at 2000 UTC in the CTRL1 simulation, which is associated with the consumption of $700 \mathrm{Jkg}^{-1}$ of CAPE between 2000 and 2100 UTC.

Nighttime precipitation is also observed in the West4 regime. However, in contrast with the East3 regime, the NRAS8 experiment succeeds at simulating this precipitation. This is due to the difference in the spatial scale of the meteorological systems acting in the region during both regimes, because in West 4 the nocturnal precipitation is associated with both the propagation of squall lines, which originate in the northeast and synoptic scale stratiform cloud bands (Rickenbach 2004). In this regime, the NRAS8 precipitation shows a gradual increase, in phase with $\mathrm{H}$ and $\mathrm{LE}$, and attains a maximum of $1.6 \mathrm{~mm} \mathrm{~h}^{-1}$ at 1800 UTC, while the CTRL1 experiment shows a maximum of $1.8 \mathrm{~mm} \mathrm{~h}^{-1}$ at $1700 \mathrm{UTC}$.

The diurnal cycle of $Q_{1}$ is shown in Fig. 6. In the CTRL1 experiment, the average cloud height is $14 \mathrm{~km}$, with maximum heating rates of $24 \mathrm{Kday}^{-1}$ at $1300 \mathrm{UTC}$ at $6 \mathrm{~km}$. In the NRAS8 experiment, the maximum heating occurs at 1700 UTC but is more intense in the East3 regime, with rates reaching $24 \mathrm{Kday}^{-1}$, while in the East2 regime they do not exceed $20 \mathrm{Kday}^{-1}$, both occurring at an altitude of $4.5 \mathrm{~km}$. In the west regimes, the time of the $Q_{1}$ maximum is little altered, although the intensity is relatively larger in the NRAS8 experiment. In the West4 regime, the NRAS8 experiment reproduces the nocturnal convective activity, with a $Q_{1}$ maximum of around $4.5 \mathrm{Kday}^{-1}$ at $6 \mathrm{~km}$. In this same regime, the CTRL1 experiment shows two maximums, the first at 1500 UTC and the second at 1700 UTC, consistent with the rainfall diurnal cycle (Fig. 5).

\section{Summary and suggestions}

The simulation results are evaluated through data collected during the TRMM-LBA experiment. The model sensitivity to the CTF implementation is analyzed. The precipitation observed through S-POL radar exhibits a well-pronounced maximum in the late afternoon, typical of continental regions during the summer. In general, the experiments overestimate precipitation during the day and underestimate (or do not simulate) nighttime precipitation, as was identified in previous studies (Betts and Jakob 2002; Collier and Bowman 2004); however, positive impacts on the simulation of the diurnal cycle of rainfall after the implementation of the JS03 CTF are identified.

The precipitation maximum in the CTRL1 experiment occurred at 1400 UTC (1000 LT) while, in the NRAS8 experiment, the maximum was at 1800 UTC (1400 HL), which is more consistent with the diurnal precipitation cycle observed by S-POL (Santos e Silva et al. 2009), with derived products from the TRMM project (Liu and Zipser 2008) and from studies conducted with pluviometer data (Marengo et al. 2004). The maximum anticipated precipitation in the CTRL1 experiment is due to the accumulation of CAPE during the first hours of the day. Thus, the reduction of CAPE in the NRAS8 experiment, which occurs due to the parcel criteria adopted by JS03, is presented as an important mechanism in the modulation of the diurnal cycle as observed by Bechtold et al. (2004). However, it was verified that the Bowen ratio is underestimated relative to the TRMM observations and previous studies over the Southeast Amazon (von Randow et al. 2004). This suggests that the large part of available surface energy is used to moisten the air, causing an increase in the buoyancy of the deepest parcels and creating clouds in the beginning of the morning, which is consistent with the mechanism proposed by Wang et al (2009), who detected an increase in the frequency of shallow clouds and a decrease in deep clouds over pasture areas, where the latent heat flux is lower compared with forested areas in the TRMM-LBA region. In terms of intraseasonal variability, the principal characteristic simulated by the model is a reduction in CAPE during east regimes (Strong et al. 2005). At the same time, the profiles show a maximum at low levels, in agreement with high-resolution simulations conducted by Lang et al. (2007).

The present work does not indicate an ideal method for simulating the rainfall diurnal cycle. However, it is shown that it is possible to obtain advances through improvements in the formulation of the algorithm that is responsible for triggering convection. With this, not only the diurnal cycle but also the spatial distribution of precipitation, was better simulated over the Amazon basin. However, additional studies are necessary in order to verify the robustness of the methodology adopted.

Acknowledgements This work is supported by National Counsel of Technological and Scientific Development "Conselho Nacional de Desenvolvimento Científico e Tecnológico" CNPQ, Brazil.

\section{References}

Bechtold P, Chaboureau JP, Beljaars A, Betts AK, Koller M, Miller M, Redelsperger JL (2004) The simulation of the diurnal cycle of convection precipitations over land in a global model. Q J R Meteorol Soc 130:3119-3137 
Betts AK, Jakob C (2002) Evaluation of the diurnal cycle of precipitation, surface thermodynamics, and surface fluxes in the ECMWF model using LBA data. J Geophys Res 107:8045. doi:10.1029/2002JD000427

Carey LD, Cifelli R, Petersen WA, Rutledge SA (2000) Preliminary report on TRMM-LBA rainfall estimation using the S-POL Radar. Colorado State University

Chou SC, Tanajura CAS, Xue Y, Nobre CA (2002) Validation of the coupled Eta/SSiB model over South America. J Geophys Res 107:D20. doi:10.1029/2000JD000270

Cohen JCP, Silva Dias MAF, Nobre CA (1995) Environmental conditions associated with Amazonian squall lines: a case study. Mon Weather Rev 123:3163-3174

Collier JC, Bowman KP (2004) Diurnal cycle of tropical precipitation in a general circulation model. J Geophys Res 109:D17105. doi: 10.1029/2004JD004818

Del Genio AD, Wu J (2010) The role of entrainment in the diurnal cycle of continental convection. J Clim 23:2722-2738

Durieux L, Machado LAT, Laurent H (2003) The impact of deforestation on cloud cover over the Amazon arc of deforestation. Remote Sens Environ 86:132-140

Fisch G, Tota J, Machado LAT, Silva Dias MAF, Lyra R, Nobre CA, Dolman AJ, Gash J (2004) The convective boundary layer over pasture and forest in Amazônia. Theor Appl Climatol 78:47-59

Freitas SR, Longo KM, Silva Dias MAF, Chatfield R, Silva Dias PL, Artaxo P, Andreae MO, Grell G, Rodrigues L, Fazenda A, Paneta J (2009) The coupled aerosol and tracer transport model to the Brazilian developments on the regional atmospheric modeling system (CATT-BRAMS) - part 1: model description and evaluation. Atmos Chem Phys Discuss 7:8525-8569

Greco S, Swap R, Garstang M, Ulanski S, Shipham M, Harriss RC, Talbot R, Andreae MO, Artaxo P (1990) Rainfall and surface kinematic conditions over Central Amazonia during ABLE 2B. J Geophys Res 95:17001-17014

Grell GA (1993) Prognostic evaluation of assumptions used by cumulus parameterization. Mon Weather Rev 121:764-787

Grell GA, Devenyi D (2002) A generalized approach to parameterizing convection combining ensemble and data assimilation techniques. Geophys Res Lett 29:1693. doi:10.1029/2002GL015311

Grell G, Dudhia J, Stanffer DR (1994) A description of the fifthgeneration Penn State/NCAR Mesoscale Model (MM5). NCAR Technical Note. TN $398+$ STR, p 122

Halverson JB, Rickenbach T, Roy B, Pierce H, Williams E (2002) Environmental characteristics of convective systems during TRMM-LBA. Mon Weather Rev 130:1493-1509

Jakob CA, Siebesma AP (2003) A new subcloud model for mass-flux convection schemes: influence on triggering, updrafts properties, and model climate. Mon Weather Rev 131:2765-2778

Kain JS, Fritsch JM (1992) The role of the convective "trigger function" in numerical forecasts of mesoscale convective systems. Meteorol Atmos Phys 49:93-106

Kousky VE (1980) Diurnal rainfall variation in northeast Brazil. Mon Weather Rev 108:488-498

Krishnamurti TN, Gnanaseelan C, Chakraborty A (2007) Prediction of the diurnal change using a multimodel superensamble. Part I: precipitation. J Clim 135:3613-3632

Kuang Z, Bretherton C (2006) A mass-flux scheme view of a highresolution simulation of a transition from shallow to deep cumulus convection. J Atmos Sci 63:1895-1909

Lang S, Tao W, Cifelli R, Olson W, Halverson J, Rutledge S, Simpson J (2007) Improving simulation of convective systems from TRMM-LBA: easterly and westerly regimes. J Atmos Sci 64:1141-1164

Lima MA, Wilson JW (2008) Convection storm initiation in a moist tropical environment. Mon Weather Rev 136:1847-1864
Liu CE, Zipser J (2008) Diurnal cycles of precipitation, clouds, and lightning in the tropics from 9 years of TRMM observations. Geophys Res Lett 31:L06116. doi:10.2029/2007GL032437

Machado LAT, Laurent H, Lima AA (2002) Diurnal march of the convection observed during TRMM-WETAMC/LBA. J Geophys Res 107:D20. doi:10.1029/2001JD000338

Machado LAT, Lauren H, Dessay N, Miranda I (2004) Seasonal and diurnal variability of convection over the Amazonia: a comparison of different vegetation types and large scale forcing. Theor Appl Climatol 78:61-77

Marengo JA, Fisch G, Morales C, Vendrame I, Silva Dias PL (2004) Diurnal variability of rainfall in Southwest Amazônia during the LBA-TRMM field campaign of the Austral summer of 1999. Acta Amazônica 34:593-603

Negri AJ, Adler RF, Xu L, Surratt J (2004) The impact of Amazonian deforestation on dry season rainfall. J Clim 17:1306-1319

Pereira LG, Rutledge SA (2006) Diurnal cycle of shallow and deep convection for a tropical land and ocean environment an its relationship to synoptic wind regimes. Mon Weather Rev 134:2688-2701

Rickenbach TM (2004) Nocturnal cloud systems and the diurnal variation of clouds and rainfall in Southwestern Amazonia. Mon Weather Rev 132:1201-1219

Rickenbach TM, Nieto Ferreira R, Halverson J, Halverson DL, Silva Dias MAF (2002) Modulation of convection in the southwestern Amazon basin by extratropical stationary fronts. J Geophys Res 107:8040. doi:10.1029/2001JD000263

Rio C, Houdin F, Grandpeix JY, Lafore JP (2009) Shifting the diurnal cycle of parameterized deep convection over land. Geophys Res Lett 36:L07809. doi:doi:10.1029/2008GL036779

Rocha HR, Goulden ML, Miller SD, Menton MC, Pinto LDVO, Freitas HCF, Figueira AM (2004) Seasonality of water and heat fluxes over a tropical forest in eastern Amazonia. Ecol Appl 14:S22-S32

Roy SR, Avissar R (2002) Impact of land use/land cover change on regional hydrometeorology in Amazonia. J Geophys Res 107: D20. doi:10.1029/2000JD000266

Saad S, Rocha H, Silva Dias M, Rosoleem R (2010) Can the deforestation breeze change the rainfall in Amazonia? A case study for the BR-163 highway region. Earth Interactions 14:1-25

Santos e Silva CM, Gielow R, Freitas SR (2009) Diurnal and semidiurnal rainfall cycles during the rainy season in SW Amazonia, observed via rain gauges and estimated using S-band radar. Atmos Sci Lett 10:87-93

Sato T, Miura H, Satoh M, Takayabu TN, Wang Y (2009) Diurnal cycle of precipitation in the tropics simulated in a global cloudresolving model. J Clim 22:4809-4826

Schumacher C, Zhang MH, Cielsielski PE (2007) Heating structure of the TRMM field campaigns. J Atmos Sci 64:2593-2610

Silva Dias MAF, Petersen C, Silva Dias PL, Cifelli R, Betts AK, Gomes AM, Fisch G, Lima MA, Longo M, Antonio MA, Albrecht RI (2002a) A case study of the organization of convection into precipitating convective lines in the Southwest Amazon. J Geophys Res 107:39.139.20

Silva Dias MAF, Rutledge S, Kabat P, Silva Dias PL, Nobre CA, Fisch G, Dolman AJ, Zipser E, Garstang M, Manzi AO, Fuentes JD, Rocha HR, Marengo J, Plana-Fattori A, Sá LDA, Alvalá RCS, Andreae MO, Artaxo P, Gielow R, Gatti L (2002b) Cloud and rain processes in a biosphere atmosphere interaction context in Amazon region. J Geophys Res 107:8072. doi:10.1029/ 2001JD000335

Strong C, Fuentes JD, Garstang M (2005) Daytime cycle of low-level clouds and the tropical convective boundary layer in Southwestern Amazonia. J Appl Meteorol 44:1607-1619

Tiedtke JM (1989) A comprehensive mass flux scheme for cumulus parameterization in large-scale models. Mon Weather Rev 117:1779-1800 
Tost H, Jockel P, Lelieveld L (2006) Influence of different convection parameterizations in a GCM. Atmos Chem Phys 6:54755493

Von Randow C, Manzi AO, Kruijt B, Oliveira PJ, Zanchi ZB, Silva RL, Hodnett RL, Gash J, Elbers JA, Waterloo MW, Cardoso FL, Kabat P (2004) Comparative measurements and seasonal variations in energy and carbon exchange over forest and pasture in South West Amazonia. Theor Appl Climatol 78:5-26

Walko R, Band L, Baron J, Kittel F, Lammers R, Lee T, Ojima D, Pielke R, Taylor C, Tague C, Tremback C, Vidale P (2000) Coupled atmosphere-biophysics-hydrology models for environmental modeling. J Appl Meteorol 39:931-944

Wang J, Bras R, Eltahir E (2000) The impact of observed deforestation on the mesoscale distribution of rainfall and clouds in Amazonia. J Hydrometeorol 1:267-286
Wang J, Chagnon F, Williams E, Betts A, Renno N, Machado LAT, Bisht G, Knox R, Bras RL (2009) Impact of deforestation in the Amazon basin on cloud climatology. Proc Natl Acad Sci U S A 106:3670-3674

Wu C, Stevens B, Arakawa A (2009) What controls the transition from shallow to deep convection? J Atmos Sci 66:1793-1806

Yanai M, Esbensen S, Chu JH (1973) Determination of bulk properties of tropical cloud clusters from large-scale heat and moisture budgets. Journal of the Atmospheric Science 30: $611-627$

Yang S, Smith EA (2006) Mechanism for diurnal variability of global tropical rainfall observed for TRMM. J Clim 19:5190-5226

Yang S, Kuo K, Smith EA (2008) Persistent nature of secondary diurnal modes of precipitation over oceanic and continental regimes. J Clim 21:4115-4131 